\title{
Turn-taking and gender differences in language classroom
}

\author{
Kaukab Abid Azhar \\ Nayab Iqbal \\ Barrett Hodgson University, Karachi, Pakistan
}

\begin{abstract}
:
The study aims at studying gender differences in the ways male and female students take turns and participate in a mixed-gender classroom. Two groups of first-year English compulsory classes held at two different departments (Geography and Economics) at the University of Karachi took part in the study. The results revealed that in the Geography Department, where there was a female teacher, male students were more dominating as compared to the female students who hardly participated in the class. They took more turns and participated better in the classroom discussion. In addition, they also interrupted the teacher and the female counterparts when they tried to contribute to the discussion. On the other hand, at the Department of Economics, female students had more number of turns. They dominated the classroom as compared to the male students. Besides, the study revealed that the gender of the teacher played an important part in shaping the discourse taking place in the classroom.
\end{abstract}

Keywords: Classroom Discourse, Classroom Participation, ELT, Gender Differences, Turn-taking,

\section{Introduction}

Gender difference has been an area of interest for a long period of time. Initially, the differences between genders were restricted to the ways males and females are expected to behave in a particular context depending on the culture they belong to. As interest in studying language from a variety of perspectives grew, people started observing the gender differences in the ways males and females use language in different contexts. In the beginning, researchers Lakoff (1975), Cameron and Coates (1985) and Trudgil (1972) studied such differences with a specific focus on the vocabulary, adjectives, amount of talk and pronunciation style used by both male and females while talking for different purposes. Now, the focus has shifted to the conversational strategies used by men and women in mixed-gender conversation to maintain their individuality or to assert their dominance. Samar and Alibakshi (2007) analyzed the linguistic strategies used by male-male, male-female and female-female communication. The results indicated a significant difference in the use of linguistic strategies in male-male, female-female and male-female 
communication. However, the research also focused upon the role of gender and experience, power and education of interlocuters in the use of linguistic strategies. Among the different conversational strategies used by people during the conversation, turn-taking is an essential strategy to continue the flow of conversation and to convey one's idea completely and at a proper time.

Behavior of men and women, both expected and observed, is determined by the culture they are born into. A major part of this depends upon how they speak and how they should speak. Women are generally stereotyped as being more talkative than men, however; an earlier study by Tannen (1984) suggest that women are interrupted more by men, which plays an important role in theory of male dominance over female. Kandell and Tannen (1977) talked about the difference between males and females atthe workplace. They concluded that males dominated conversations by getting and holding the floor longer than females, interrupting more and making various contributions using language strategies that help maintain the status difference.

Zimmerman and West (1975) are considered as the pioneers of the research focusing upon the gender differences. West and Zimmerman (1987) explained that the differences between men and women are created by the process of social arrangement. He said that in gendered conversations and situations men portray dominance whilst women display deference. On the other hand, a recent study by Park et al (2016) explored differences in language use across gender using a social media dataset. The results revealed that the language identified by females was more polite, warmer and compassionate but they were still assertive in their language use.
In addition, Zimmerman and West (1975) discussed turn-taking as an economic system and described the differences between male and female in their number of turns as parallel to the differences between them in society's economic system. Furthermore, a recent study by Hancock and Rubin (2015) focused on the influence of communication partner's gender on language. They established that there were not any significant differences in the way men and women use language. However, participants interrupted more and used more dependent clauses while speaking with a female than with a male.

By studying turn-taking and gender differences this research article aims to find out the differences between the male and female students' participation in the classroom focusing on the gender of the teacher concentrating on the following research questions:

- Is there any difference between the turn-taking patterns observed in the two classes?

- Who dominates the classroom discussion (male/female students) in the two classes?

This research study will shed light on the turn taking patterns and turn taking strategies used by male and female students in a language classroom while taking into consideration the gender of the teachers. It will help the teachers understand how male and females contribute differently in a classroom discourse, which as a result would help them make their classes more interactive.

\section{Literature Review}

Turn-taking has been an important part of studies on gender differences. Turn-taking in this research is seen as the conversational strategy that helps maintain 
the flow of conversation by allowing the speakers to take the floor in order to contribute to the discussion that is taking place. It also includes holding the floor and yielding the floor at a particular point in the discussion.Goffman (1976). It can be considered as one of the basic mechanisms in conversation.

Aukrust (2008) discussed the participation of boys and girls in a classroom in Norway across four grades (first, third, sixth and ninth). His findings revealed that the differences between girls and boys participation were least in the first grade and most in the ninth grade. The girls were mostly found to speak when the teacher initiated the conversation by allocating turns whereas the boys had more overlapping turns with the teacher. Unlike the girls, they also gave comments when not asked by the teacher. Besides, there was less difference in their participation when the teacher was a female as compared to when the teacher was a male, whose presence accounted for more difference in participation. In the class of the male teacher, boys made many uninvited comments.

Similarly, Tannen (1995) discusses the difference between male and female in the way they organize their speech on different occasions. She concludes that men are found to be more sensitive to the power dynamics. They tend to speak in a way that keeps them in a dominant position. On the other hand, women are more concerned about the rapport dynamic and speaking in ways that save face for others. Besides that, Wang (2010) talked about gender differences in speech style in public places. The researcher used conversation analysis, interview, and questionnaire as the data collecting instruments. The study revealed men as contributing more to talk than women do in their conversation with women. It is men who always violate the rules of turn-taking and take more turns to control the conversation. Similarly, Chalak and Karimi (2017) studied turn taking system and repair strategies used by Iranian EFL learners in 10 EFL classrooms. The results indicated that female students were mostly chosen by the teacher to speak while self-selection was commonly employed by the male students.

Moreover, Aidinlou and Dolati (2013) focused on comparing male and female gender in taking turn to see which gender talks more while discussing education quality at different public and private schools in Turkey. The conversation between male and female teachers was recorded. The study revealed that female teachers talked more in discussions with their own gender. Males helped complete each other's utterances whereas females had more overlapping statements. Broadbridge (2003) examined the difference between male and female speakers during conversation using recording as a method for collecting data. The sample included two male and two female speakers who worked for the same English-language school in Tokyo. The study showed that men were the ones to interrupt most and women were interrupted most. Besides this, women were more active in listening as compared to men.

Similarly, Zhang (2010) studied the difference between male and female students in terms of participation in classroom in a Swedish school. The data was collected through classroom observation and interview with the teachers. The findings revealed that girls contributed more to the classroom talk in terms of the total number of turns and in the amount of turn length. The girls were also found to be better at elaborative talk as compared to the boys. Furthermore, Wolfe (2000) analyzed ethnic and gender differences in classroom conversational styles in a face-to-face and computer- 
mediated discussion. The results revealed that white males were found to participate more in a face-to-face discussion whereas white women were more comfortable having a discussion in a computermediated setting. On the other hand, Hispanic women contributed frequently in a face-to-face conversation, spoke more than Hispanic males and disliked computer-mediated settings. The research study helped to understand how gender differences may vary across cultures.

In addition, Martin and Marsh (2005) explored the impact of students' and teachers' gender and their interaction on academic motivation. The study revealed that academic motivation and engagement did not vary as a result of the teacher's gender. In terms of academic motivation and engagement boys did not show any differences in the class of a male or a female teacher.

Like all these research studies, the current research study aims at studying the turntaking patterns. However, the specific focus of this article is to analyze the turn-taking patterns of a classroom discourse, taking the gender of the students and teachers into consideration.

\section{Methodology}

The research was based on Qualitative Research Paradigm as it helps explore any issue in depth. It is not only conducted in a natural setting but also helps collect reliable data in terms of one to one interaction between the researchers and their participants.

Convenient sampling was used for selecting the research participants. The classes that were easily accessible were selected for observing the turn-taking patterns occurring in the classroom setting. However, it was made sure that the classes consisted of the students of both the gender as the aim of the research was to observe gender differences.

Discourse analysis was used as a method to analyzeconversation taking place in the class. It is a qualitative method of analyzing the texts focusing on the connection between language, power, and social practices. Discourse can be defined as a way of speaking that does not only reflects social relations but construct them. (Fairclough, 1992). The method helps to examine the conversation with a specific focus on the meanings derived from a particular context.

In the current research, conversational exchange taking place in the classroom between teachers and students and between students are observed to see if the gender difference exists in the way male and female students interact in the classroom environment. Compulsory English classes for the 1st year Honors students held at the Department of Geography and Economics were observed. A female teacher conducted the session observed at the Department of Geography whereas a male teacher instructed in the class observed in the Economics Department. Both male and female teachers' classes were observed to note if the difference in participation between the male and the female students was because of the gender of the teacher or if it remains the same irrespective of the gender of the teacher.

In order to collect data, classrooms were observed using field notes and informal discussions with the teachers who participated in the study. The observation was a primary data collecting instrument as it helps collect first-hand data and allows the researcher to focus on all the aspects that play an important part in constructing the social phenomena under study.

The study was based on unstructured observation as it has an edge over structured observation because of the 
diversity that can be studied through it. (Gevin, 2008). Besides, structured observation helps focus only on the aspects the researcher considers related to the study based upon his/her prior knowledge whereas unstructured observation allows a study of all the critical events that may influence behaviors observed hence, proposing new and varied dimensions to be focused upon. Therefore, everything from the topic of discussion to the body language, disturbance and silence were observed to collect reliable data. Two of our friends helped us gain access to the teachers instructing at the respective departments. As part of ethical consideration, the consent form was signed by the teachers. After the teachers' approval, further research was conducted. To minimize the chance of collecting any contaminated data, the first three sessions were used as piloting so that the students become

\begin{tabular}{|l|c|c|c|}
\hline $\begin{array}{c}\text { Number of } \\
\text { Sessions }\end{array}$ & $\begin{array}{c}\text { Number of } \\
\text { Students Present } \\
\text { (Boys, Girls) }\end{array}$ & $\begin{array}{c}\text { Number of } \\
\text { Turns (Boys) }\end{array}$ & $\begin{array}{c}\text { Number of } \\
\text { Turns (Girls) }\end{array}$ \\
\hline Session 1 & 17,31 & 28 & 25 \\
\hline Session 2 & 18,34 & 52 & 40 \\
\hline Session 3 & 12,26 & 61 & 28 \\
\hline
\end{tabular}
familiar with the presence of the stranger and perform in their normal way.

Field notes help keep track of important events discussed as part of the research. It helps to keep a record of all the events that play a significant role in the development of the phenomena under study. (Thomas, 2015).While observing the classes, field notes were taken. Moreover, in order to cross-check the data that was collected an informal interview with

\begin{tabular}{|l|c|c|c|}
\hline $\begin{array}{c}\text { Number of } \\
\text { Sessions }\end{array}$ & $\begin{array}{c}\text { Number of } \\
\text { Students Present } \\
\text { (Boys, Girls) }\end{array}$ & $\begin{array}{c}\text { Number of } \\
\text { Turns (Boys) }\end{array}$ & $\begin{array}{c}\text { Number of } \\
\text { Turns (Girls) }\end{array}$ \\
\hline Session 1 & 7,30 & 2 & 16 \\
\hline Session 2 & 6,31 & 9 & 37 \\
\hline Session 3 & 11,26 & 10 & 18 \\
\hline
\end{tabular}
the teachers was conducted. The discussion was mainly based upon inquiring the difference of performance in male and female students, their interaction in class and with the teachers separately (if they had any) and their response when asked to contribute to the ongoing discussion in the class. Informal interview helps get significant information about a particular subject of study. It also helps togain insight into the subject under research.

\section{Data Analysis}

The section discusses the number of turns taken by both male and female students in the sessions observed at the Department of Geography and the Department of Economics.

Table 4.1: Number of Turns taken by Male and Female Students at the Department of Geography

Table 4.2: Number of Turns taken by Male and Female Students at the Department of Economics
Although six sessions were observed, the data presented is only for three sessions as the observation for few of the sessions were used as piloting and to avoid repetition. The boys were in minority in both the classes but their performance varied to a great extent in both the Departments. The presence of students in such a large classroom cannot be controlled, therefore; the above table 
presents the number of students that were present on the day of observation. Sacks, Schegloff, and Jefferson (1974) in their article mentions some of the ways in which turns are organized in a conversation. The turn-taking patterns of the classroom were analyzed using their model of turn-taking. The model refers the following patterns in the conversation being observed:

1. Speaker change recurs, or at least occurs.

2. Overwhelmingly one party talks at a time.

3. Occurrences of more than one speaker at a time is common but limited.

4. Transitions with no gap and overlap are common.

5. Turn order is not fixed, but varies.

6. Turn size is not fixed, but varies.

7. Length of conversation is not specified in advance.

8. What parties say is not specified in advance.

9. Relative distribution of turns is not specified in advance.

10. Number of parties can vary.

11. Talk can be continuous or discontinuous.

12. Turn-allocation techniques are used.

\section{Findings and Discussion}

In the department of Geography, where the teacher was a female, the male students dominated the class in terms of the number of turns during the conversation. They took the floor to speak very often and participated in almost each and every discussion in the class. Two of the girls sitting at the front row took part whereas the girls sitting at the back rows mostly remained silent in the class.
Teacher: What does the term 'Global Village' means?

Boy: Ma'am it means that the world has become advanced

The teacher asked the students to locate topic sentences of all the paragraphs given in a text related to Global Village. However, this discussion was mostly based upon the IRF (Initiate-Response-Feedback) exchange in which the teacher asks questions and the students respond, followed by teacher's feedback. Even in this situation, boys responded and participated more as compared to the girls. For instance;

Teacher: Locate the topic sentences of the 1st paragraph

Boy 1: The first sentence is a topic sentence

Teacher: Good, second para?

Boy 2: Ma'am the second sentence

(shows overlap in conversation between the two boys)

Another boy: No ma'am the first one

Teacher: Yes, it's the first one

However, boys also took the floor themselves for speaking and not only when asked questions, so the class was not always based upon the IRF exchange between the teacher and the students. The turn order and size were not fixed, and the boys took more turns as compared to the girls in the class.

According to the rules of turn-taking, one speaker is supposed to speak at a time. However, boys violated this rule by interrupting the teacher's lecture as well as the female students' comments on the topic of discussion. For example, in one of the classes, in the middle of the discussion, one 
of the boys interrupted to give an excuse for not completing his homework, disturbing the entire class. The teacher scolded and punished one of the boys for interrupting the lecture repeatedly, and she asked him to leave the class. Similarly, they interrupted one of the girls when she tried to answer a question asked by the teacher.

Teacher: What is the difference between a fact and an opinion?

A girl: $M a^{\prime} a m$ fact means

Boys: awaaznahiaarahi (we can't hear you)

They also interrupted the teacher;

Teacher: So while writing a summary you have to

2 Boys (entering the class): assalaam-oalaikum (Greetings)

Teacher: Why don't you people go back, greet each other and then come back to the class?

Teacher: now you people have to write a summary

A boy: of the first paragraph

Teacher: Do we summarize only one paragraph or the entire text while writing a summary? Did I say you have to write a summary only for the first paragraph?

The boys were found to interrupt the teacher during her lecture many times like the ones discussed above, as when they started speaking before the teacher completed her utterance, which shows the dominance of the male students. Moreover, it was also noticed that whenever the teacher asked any questions related to the task or homework, for example 'have you done the task?' the boys shouted loudly in affirmation in contrast to the girls. They deliberately made noise most of the times in the class. On one occasion, instead of doing the task, two of the boys talked at the back and were reprimanded by the teacher. On some occasions the boys deliberately disturbed the teacher:

Teacher: Has everyone submitted their assignment to the CR?

CR (A girl): Ma'am girls ne dia boys nenahidia

Boys: humenahipata $k C R$ kaun he

(CR: Ma'am girls have submitted their assignments but boys have not; Boys: We do not know who the CR is)

Teacher: I made the CR the first day and you people do not even know about the CR, great! Submit your assignments to me right now.

The way the male students responded on some occasions like the one mentioned above showed that they intentionally interrupted and disturbed the teacher.

As per the rules of turn-taking mentioned in the model discussed above, in some situations, turns are allotted to the speakers in advance to speak. In one of the classes, the teacher asked students to write a story about a bad experience with any of their teachers in their childhood as an activity for the chapter 'Recounting Past.' The teacher asked the students to come to the front of the class and share what they had written on the given topic. At first, she did not assign the turn individually. The boys voluntarily came and shared their stories in the class. They were more enthusiastic to participate as well as confident enough to share their stories whereas the girls at first were hesitant to mount the dais to share their stories until and unless the teacher herself selected the girls and forced them to do so and participate in the class. 
Teacher: Why are the girls so reluctant to participate in the class? You people are marked for speaking in the class. The girls won't get the marks if they do not come and share their stories.

In one of the classes, the teacher discussed a text named 'Gender Discrimination at Workplace in Pakistan'. She asked the students to locate if the given statements can be considered as a fact or as an opinion..The boys talked among themselves while given a task, whereas the girls mostly remained silent throughout the class. Although the topic was related to women, the boys were the one to participate more. This time as well the conversation was initially based upon the IRF exchange with the teachers giving the statement and asking the students to classify them as facts or opinions.

Teacher: 'Women are more jealous than men', is it a fact or an opinion?

Boys: It's a fact ma'am.

Teacher: Women are more spend thrift than men

Boys: Hundred percent, ma'am.

Teacher: Women are more intelligent than men.

Girls: True, ma'am

A boy: Ma'am, it is a printing error

Following this discussion, the boys began commenting on how men were superior to women. They were so enthusiastic that they kept on debating with the two girls presenting the counter-argument on some occasions.

A boy: Women are physically weak so they should not work.
A girl: Behind every successful man, there is a woman

\section{A boy: How many women are scientists?}

Another boy: Women cannot even do business

Boys were found holding the floor almost throughout this session. This was the class where the speaker change rarely occurred and even the teacher was unable to speak in some instances. This, however, could again be attributed to the gender of the teacher. As the teacher was a female, she, despite being in an authoritative position, was found to remain silent in the conversation. She did not get a chance to respond many times during this discussion. She was unable to control the conversation as the male students were quite dominating in her class, specifically on that particular day. Also, the fact that the teacher was young and inexperienced can be considered as another reason behind her lack of control especially when it comes to dealing with the male students.

Throughout the discussion, boys were the ones to speak and contribute more. They were more vocal than the girls despite being in minority. We expected the girls to participate more when the topic to be discussed was announced in the class but, like all the other classes, boys dominated and held the floor a lot longer than the girls in the entire session. This could also be attributed to other factors like students' prior educational experience and culture. Most of the girls have studied from girls 'college previously, so they take time to adjust and express themselves especially in the presence of male students. The other reason could be the lack of proficiency in English language as most of them came from a government college where English was taught through rote learning, therefore, they lacked confidence to speak in the class. 
In short, the boys in the Department of Geography were found to be more interactive than the girls. They interrupted the teacher as well as the female students whenever they tried to participate. They violated the rules of turn-taking many times. The dominance of male students in this class was in accordance with Lakoff (1973) dominance theory. According to this theory, men control the conversation with women and the language system itself. On the other hand, women use language that reflects their subordinate position as compared to men, therefore, the language used by men reveals their power more than their gender.

In the Department of Economics, where the instructor was a male, the girls dominated the classroom discussion. Besides, they were more relaxed than the boys. Although the discussion in this class was most of the time based upon IRF exchange, the girls responded more to the questions asked by the teacher. This could be because of their interests in the topic of discussion. Also, the male students were more alert in the presence of a male teacher because the male teacher was more authoritative and had a better classroom control as compared to the female teacher.

In one of the classes, the teacher discussed the number of students who opted for Economics major as their own choice. The teacher asked them to use adjectives and be expressive in sharing their experience.

Teacher: Are you people here because you like Economics?

A girl: agar aapkosona ho to Economics paRhe (If you want to sleep you

should study Economics)

Teacher: ((laughs))
The teacher interacted more with the girls as they participated more in the discussion every time. The boys did not participate most of the time. The teacher posed a direct question to one of the boys:

Teacher: Is there any other subject that you like?

Boy: I like Physics because the world obeys the laws of Physics.

On the other hand, on some occasions the girls took turns voluntarily, unlike the boys who were mostly allotted the turns:

Teacher: What about others? What is it that you people like studying?

A girl: Sir, I don't like Urdu and I don't like Economics either.

Teacher: aapko Urdu nahipasand, aap ko Economics nahipasandtoupasand kya he? (You don't like Urdu, you don't like Economics, then what is it that you like?).

Besides, in one of the classes two girls were seen talking among themselves:

Girls: ((talking among themselves))

Teacher: kya koi bohatzurruribaat ho rahe he (is there anything important that you people are discussing?)

Girls: No, sir.

Teacher: nahi hum sab kobhi batayye agar koi zuruuribaat he to (no, please let us all know if it's something important.)

But unlike the female teacher, the male teacher did not behave in a strict manner and did not punish them for disturbing the class. The difference in the way the male and female teacher controlled the class can also be attributed to the difference in their 
gender. The male teacher had an authoritative position as compared to the female teacher who in some instances lost control of the class. On the other hand, the male teacher had complete command on his class. The female teacher was young and less experienced as well, so age and experience can be another reason behind her lack of class control.

In the next class, the teacher conducted a listening activity. He asked the students about the advantages of the internet as a pre-listening activity, telling them to have a peer discussion and to jot down their points within three to four minutes. The teacher walked around in the class after assigning the task. Three of the boys sitting together called him to their seat and discussed their answers with him. Then, a boy sitting separately also called the teacher to his place. At the time of discussion, the girls participated and voluntarily spoke more as compared to the boys.

Teacher: What are some of the advantages of internet, besides the ones mentioned in the text?

A girl: Online shopping.

Teacher: ha aap logo $k$ lie to ye bohatbara advantage hoga (yes, this would be one of the greatest advantages of internet for you people) What else?

\section{A girl: Marketing}

Teacher: Again shopping? ((laughs))

Girl: No sir, marketing different products.

Teacher: oh me samjhaaap sab yehikarteyrehtey he internet pe (oh I thought you people only shop online over the internet.)

Another girl: Sir, freelance work.
Teacher: Ok boys, ((points towards a boy))

A boy: Internet helps in online banking and it also helps find locations through Google maps.

Teacher: Very good.

The male students were quite reluctant to participate. They only participated when the teacher directly asked them to answer and did not take the turn to speak on their own.

The teacher then commenced the listening activity by reading a passage and asked the students to locate which character had spoken the asked statements in the passage that was just read. There were three characters Ayesha, Fatima and Fatima's mother. The teacher gave different words and asked the students to relate it with the character that had used the word in the text that they had just listened to. The entire class participated together. However, the girls were more vocal and energetic in their participation. Then the teacher asked different questions related to the passage and the students themselves took turns to answer. One of the boys started to answer one of the questions when he was interrupted by a girl:

Teacher: Why didn't Ayesha come to college?

\section{A boy: Because she was}

A girl: Sir, she stayed awake all night to chat that's why she didn't come to college

The girl not only interrupted him but also continued to answer the question whereas the boy remained silent from then on.

In the Department of Economics, the turntaking patterns were totally different than those observed in the Geography 
Department, where the boys dominated the classroom discussion most of the times. However, sometimes there was no participation in the class by both the boys and the girls in the Economics Department. In one of the classes, the male teacher was found saying:

Teacher: What is wrong with the class? Am I talking about rocket science that you people are so reluctant to speak in the class?

Although the girls in this department were also not that interactive, they still dominated the class with their contribution to the classroom discussion as compared to the boys who most of the times were observed to be passive listeners only. The way males and females students interacted in this particular class was in sharp contrast to the Lakoff (1973) dominance theory which suggest that men are always the ones to assert their power and dominance in a mixed-gender conversation. Therefore; the theory can be criticized for not making allowances for the individual differences and situational factors.

Moreover, we had an informal discussion with the teachers to cross-check the data that was collected through the classroom observation. We asked the female teacher if she thinks the boys participated more, to which she replied in the affirmative. She said that boys were very energetic and more willing to participate in the class. She also said that girls hardly participated in the class discussion, except for the two girls sitting in the front row. When asked if the girls approached her to discuss things privately, the teacher replied in the negative. She also said that usually, girls approach her to discuss things separately but in this class boys are the ones to do so.

She also said that boys were mostly active in class if the teacher is a female. Moreover, she revealed that sometimes the boys created a lot of disturbance in the class due to which she scolds them in order to control the class. Apart from talking, she said, the boys were quite good in their class performance. She was also asked if she thinks that the girls do not participate because they lack proficiency in English language. To this, she answered negatively. She said that even boys have language problems yet they speak and take part in the classroom discussion. Besides, she was also asked if she thinks that girls do not speak because of the presence of the boys. She replied that his might be the reason as boys interrupted and even made fun of the girls sometimes when they tried to participate.

We started the discussion with the male teacher sharing our observation that girls participated more in the class whereas the boys hardly did so. The teacher replied in the affirmative, saying that boys do not participate until and unless you ask them to do so whereas the girls participate voluntarily. The teacher was then asked about the reasons that he considered as the cause of the boys' lack of performance in the class to which he said that this could be because of the overwhelming presence of the girls, as the boys were in the minority. He also claimed that the boys were shy to participate in the class. He further said that one of the boys approached him personally and confided that his lack of proficiency in the English language made him unwilling to attend the class.

Besides, the teacher said that there was a boy who completed all the assigned tasks but still hesitated to participate in the class discussion. He also said there are two other boys who are from the Northern areas who were so shy that they just smiled at the teacher whenever he asked them a question. Then, the teacher was asked if the boys were hesitant to participate because of their pronunciation problems. The teacher agreed on this as a probable cause 
as he felt that the males were very conscious of their self-esteem so they might skip answering out of fear of giving incorrect answers, especially in the presence of the female students. The teacher also said that even though the girls also face language issues, it is the boys who lack the confidence to participate. The teacher said that when he approached the three boys sitting together and asked them to share what they had written on the given task, they passed the sheet to one another because of shyness or their lack of confidence. The teacher was also asked if the boys visit him personally to discuss things. He answered that the boys do come to discuss things with him personally but are reluctant to participate in front of the class.

\section{Conclusion:}

The present study revealed quite obvious differences between the participation of the male and female students in both of the classes that were observed. The boys were found to talk more, interrupt more and participate more enthusiastically in the class where the teacher was a female whereas, in the class of a male teacher, the boys were the passive listeners, participating only when asked direct questions by the teacher. Similarly, the girls were found to participate actively in the class where the teacher was a male, while the girls hardly participated in the class of a female teacher. The boys were found to dominate when the teacher was a female, whereas the boys were found to be very conscious in the presence of a male teacher. The boys in the Economics Department minded their behavior in the presence of their teacher, who was a male. Their demeanor was deferential, which can be attributed to the gender of their teacher. To sum up, the study reveals that gender differences do exist in the way male and female students interact in the classroom. Also, the gender of the teacher plays an important part in shaping the classroom discourse.

\section{Limitation and Future Research}

The present study cannot be generalized as it was conducted in higher education language classes of Pakistan. Future studies can be carried out at different levels to validate the findings of our study. This study is based on a qualitative research design, future studies may include a quantitative framework to investigate the same research area.

\section{References}

Aindinlou, N., \& Dolati, K. (2013). A Comparison Study of Males and Females Turn-taking Frequency in Turkish.Journal of Basic and Applied Scientific Research, 3(1), 45-47.

Aukrust, V. G. (2008). Boys' and girls' conversational participation across four grade levels in Norwegian classrooms: taking the floor or being given the floor? Gender and Education, 20(3), 237-252. https://doi.org/ $10.1080 / 09540250802000413$

Broadbridge, J. (2003). An investigation into differences between women's and men's speech. The University of Birmingham Centre for English Language Studies, 1-26.

Cameron, D., and Coates, J. (1985) Some problems in the sociolinguistic explanation of sex differences. Language and communication, 5:143-51.

Chalak, A., \& Karimi, M. (2017). Analysis of Turn Taking and Repair Strategies among Male and Female Iranian Intermediate EFL Learners. Journal of Applied Linguistics and Language Research. 4(2), 1-9. www.jallr.com 
Fairclough, N. (1992). Discourse and Text: Linguistic and Intertextual Analysis within Discourse Analysis. Discourse and Society, 3(2), 193-217. https:// d o i . o r g / $10.1177 /$ 0957926592003002004

Given, L. M. (2008). The SAGE Encyclopedia of Qualitative Research Methods, 1-0. Thousand Oaks, CA: SAGE Publications, Inc. doi: 10.4135/ 9781412963909

Goffman, E. (1976). Replies and responses. Language in Society, 5(3), 257-313. h t t ps:// doi.org / 10.1017 / S0047404500007156

Hancock, A. B., \& Rubin, B. A. (2015). Influence of Communication Partner's Gender on Language, Influence of Communication Partner's Gender on Language. Journal of Language and Social Psychology, 34(1), 46-64. https://doi.org/ $10.1177 / 0261927$ X14533197

Kendall, S., \& Tannen, D. (1977). Gender and Language in workplace: In Wodak, R (Eds) Gender and Discourse, London: Sage Publications.

Lakoff, R. (1973). Language and Woman's Place. Language in Society, 2(1), 45-80.

Lakoff, R. (1975). Language and woman's place. Language and society, 2, 45-79.

Martin, A., \& Marsh, H. (2005). Motivating Boys and Motivating Girls: Does Teacher Gender Really Make a Difference?

Australian Journal of Education, 49(3), 320-334. https:// doi.org/10.1177/ 000494410504900308

Park G, Yaden DB, Schwartz HA, Kern ML, Eichstaedt JC, Kosinski M, et al. (2016) Women are Warmer but No Less
Assertive than Men: Gender and Language on Facebook. PLoS ONE 11(5): e0155885. https://doi.org/ 10.1371/journal.pone.0155885.

Samar, R., \& Alibakshi, G. (2007). The Gender Linked Differences in the Use of Linguistic Strategies in Face-to-Face Communication. Linguistic Journal, 3(2), 59-71. http:// www.cs.columbia.edu/ sbenus / $\mathrm{T}$ e a c h i n g / A P T D / Samar_Alibakschi_gender_face-toface_Linguistic_journal_2007.pdf

Sacks, H., Schegloff, E. A., \& Jefferson, G. (1974). A Simplest Systematics for the Organization of Turn-Taking for Conversation. Language, 50(4), 696735. https:// doi.org/10.2307/412243

Schwandt, Thomas. (2015). The SAGE Dictionary of Qualitative Inquiry. 4th edition. Thousand Oaks, CA: SAGE.

Tannen, D. (1984) Conversational Style: Analyzing Talk among friends. Norwood:Albex.

Tannen, D. (1995). The Power of Talk: Who Gets Heard and Why. Harvard Business Review, 73(5), 138-148.

Trudgill, P. (1972) Sex, Covert Prestige and Linguistic Change in the Urban BritishEnglish of Norwich. Language in Society, 1 (2), 179-195, Oct 72.

Wang, M. (2010). A Study on Gender Differences of English Speech Style in Public Places. In 2010 International Conference on E-Product E-Service and E-Entertainment (pp. 1-4). https:// doi.org/10.1109/ICEEE.2010.5660837

West, C., \& Zimmerman, D. (1987). Doing gender. Gender and Society, 1(2), 125151. 
Wolfe, J. (2000). Gender, Ethnicity, and Classroom Discourse: Communication Patterns of Hispanic and White Students in Networked Classrooms. Written Communication, 17(4), 491519. https://doi.org/10.1177/ 0741088300017004003

Zhang, H. (2010). Who dominates the class, boys or girls? (Thesis, Kristianstad University).

Zimmerman, D. ,\& West, C. (1975). Sex roles, Interruptions and Silences in Conversation, In Thorne, B. \& Henley, N (Eds.), Language and Sex: Difference and Dominance, 105-129. Rowley, Mass: Newbury House Publisher.

\section{Contributors}

Nayab Iqbal received her master's degree from the University of Karachi in 2014 with a major in English Linguistics. She is currently working as a Lecturer at the Barrett Hodgson University. She has been associated with the field of education for almost 5 years. Her work and research experience has helped her become an expert at managing learnercentered classrooms by employing current language pedagogical practices

Kaukab Abid is a Lecturer at Barrett Hodgson University, Karachi (Pakistan). He received his Master's degree in English Literature from University of Karachi and MBA (Marketing) from Institute of Business Management. Before becoming an academician, he gained four years of valuable work experience in leading MNCs at a Managerial level. 